\section{University of Missouri-Kansas City Info Commons wins design awards}

The University of Missouri-Kansas City (UMKC) Miller Nichols Library Information Commons has received an International Illumination Design Award "in recognition of professionalism, ingenuity, and originality in lighting design" from the Heart of America section of the Illumination Engineering Society of North America. The Information Commons has also been recognized for educational interior design excellence in American School E University magazine. In the compe- tition that has been held since 1983, the Information Commons was recognized for Outstanding Design in the category of Libraries/ Media Centers. Pictures and information about the UMKC Information Commons can be found at http://www.umkc.edu/lib/MNL/ About/info-commons.htm.

\section{Call for popular culture papers}

The Libraries, Archives, and Popular Culture Research Area of the Popular Culture Association is soliciting papers dealing with any aspect of popular culture as it pertains to li-

\title{
Digital Diamond sparkles at Temple
}

The word diamond abounds at Temple University - a constant reminder of founder Russell Conwell's stirring speech to prospective donors, retelling the tale of acres of undiscovered diamonds that a prosperous Persian farmer overlooked on his own land.

Temple Libraries recently launched Digital Diamond, an archive containing thousands of digitized images, including historical photographs of Philadelphia and the region, international war posters (one of which appears on this issue's cover), sheet music, architectural slides and photographs, and other archival materials.

It is being developed with financial support totaling more than $\$ 800,000$, comprised of a gift from a generous donor and two congressionally directed grants administered by the Institute of Museum and Library Services. True to Conwell's vision of bringing hidden treasures to light, Digital Diamond provides electronic access to selected collections previously available only to on-site users. The archive is accessible at http:// diamond.temple.edu.

Digital Diamond is an implementation of the Archival Reference Database component of Temple's online library system by Innovative Interfaces and runs parallel to the online catalog. All search features found in the online catalog are available, including keyword and advanced searching, subject searching, and scoped searches.

Unlike a typical library catalog, with archival holdings represented by a single summary statement describing an entire collec- tion, Digital Diamond features a complete MARC record for each image. Scholars who have identified useful LC subject headings while searching for materials in the online catalog can use the same headings to search in Digital Diamond for related images of interest.

\section{MARC cataloging}

The decision to do MARC cataloging for each image presented challenging issues. Templates were devised so staff scanning photographs and other materials could create brief cataloging records, later to be revised by librarian catalogers, once the images are linked in the database. Despite efforts to streamline workflow and keep pace with scanned images waiting to be linked, a backlog of scanned images developed and continues to be a challenge. A database was created to record and track the numbers of images and bibliographic records and to help alert staff members about growing bottlenecks that can be eased by adjusting work assignments.

\section{Watermarks}

Maintaining our copyright on the vast collection of photographs from the George D. McDowell Pbiladelphia Evening Bulletin Collection is imperative. While providing access to the images, we also maintain the right to sell photographic reprints upon request. Our digital imaging specialist developed a watermark that appears on each copyrighted image, and each bibliographic record provides instructions on how to re- 
braries, archives, museums, or research. Particularly welcome are papers responding to Nicholson Baker's book, Double Fold: Libraries and the Assault on Paper: Prospective presenters should send a one-page abstract by September 15 to: Allen Ellis, W. Frank Steely Library, Northern Kentucky University, Highland Heights, KY, 41099-6101, email: ellisa@nku.edu.

\section{CNI and Dartmouth offer "Collaborative Facilities" Web site}

The Coalition for Networked Information (CNI) and Dartmouth College have created a

quest a reprint. Watermarks, as well as other considerations, including cataloging issues and workflow tracking, are all detailed in Collection Management (July 2002), which also includes a bibliography on digital initiatives.

\section{Electronic course reserves}

Another component of the Digital Diamond project included using scanned images in our implementation of Innovative Interfaces' Course Reserves Module. The first images to be offered were horticultural slides regularly used for classes in landscape architecture and horticulture. Following that, other reserve materials, such as past exams and assigned articles, were gradually added to the e-reserve offerings. These items are available only to Temple users because of copyright restrictions. A complete discussion of early findings in this course reserves project, including copyright issues and further considerations, was published in The Bottom Line: Managing Library Finances (volume 14, number 2, 2001).

\section{Next steps}

Progress during every part of the first grant, completed in March 2002, was slower than originally anticipated. The pace gradually increased as staff members became familiar with scanning procedures and cataloging issues and the workflow became more standardized.

Building on the experience gained from the completed projects, the libraries are now new Web site, "Collaborative Facilities," designed to collect, organize, and disseminate information about model collaborative facilities on college and university campuses. This includes information commons; teaching, learning, and technology training facilities; and multimedia facilities.

All higher education institutions are invited to submit materials on collaborative facilities for inclusion on the Web site. The materials will be reviewed to determine that they meet the primary criteria of the Collaborative $\mathrm{Fa}$ cilities project, namely that the facilities must

using a second congressionally directed grant to increase the depth and breadth of the existing collections and to add more unique collections owned by the libraries to Digital Diamond. In addition, outcomes assessment instruments for various grant projects will be developed in collaboration with some professors who will use selected images in their lectures and assignments. Another major component of the second grant is the development of online exhibitions to create new opportunities for outreach to the university, the scholarly community, school groups, and the public.

Using lessons learned during the first grant about how easy it is to underestimate the time investment in such a project, more robust staffing is now in place for the current endeavor. Rather than relying solely on existing staff who already have full workloads, a separate full-time staff has been recruited and hired, including a project manager with a library degree and museum experience, a project assistant/curator, a scanning supervisor, and a bibliographic assistant. Part-time student assistants also work on the project.

Digital Diamond is still very much a work in progress, with more to be learned as we continue to add new materials and collections at an increasingly streamlined pace, develop outcomes assessment instruments, and use exhibition software to creatively display our image collections and tell their stories.-Carol Lang, Temple University Libraries, carol@temple.edu 
be physical spaces, involve more than one unit of the institution, and involve the use of information technology. The Web site, which includes a submission form, is at http:// www.dartmouth.edu/ collab/index.html.

\section{Columbia $U$ to preserve School of Library Services collection}

Columbia University Libraries has started a project to preserve, rehouse, and enhance access to the School of Library Service (SLS) library collection. The SLS collection is the strongest historical collection in the world for materials relating to libraries and librarianship. The collection was started in 1887 with "practice books" used by the first class of students in the first library school in the country, founded by Melvil Dewey at Columbia University. Over the course of its 100-year history, the SLS collection grew in size and scope to include all manner of material documenting every aspect of librarianship.

Over the next three years, catalog records for the collection's 110,000 volumes will be converted to machine-readable form and made accessible in CLIO, the libraries' online catalog, as well as through OCLC and RLIN. The collection will be inventoried and moved to the Research Collections and Preservation Consortium's Shelving Facility, with fragile items receiving preservation treatment.

\section{Village Voice Pubs added to Alt- Press Watch}

Proquest Company's Information and Learning unit has added seven publications from Village Voice Media Publications to its Alt-Press Watch Database. The database offers full-text content from newspapers, magazines, and journals of the alternative and independent press. Titles from Village Voice Media include the Village Voice, LA Weekly, Seattle Weekly, City Pages, Cleveland Free Times, OC Weekly, and Nashville Scene. Coverage for the weekly newspapers begins with January 2002 and continues forward. In addition, Proquest is adding Village Voice articles back to the first issue in 1955, with full text and complete indexing.

\section{Toronto, 2003: It's closer than you think}

Toronto is a world-class city and a great location for next year's ALA Annual Conference. In addition to the fact that the U.S. dollar goes a long way in Canada, Toronto offers a central convention center, in walking distance to the ballpark and theater district, and is very family friendly. Many of the major hotels are connected to an underground network that includes a variety of stores and access to the subway, so there's always time to sneak in a little shopping on the way to your next meeting.

Despite these pluses, we know that there are some concerns over the fact that attending the conference requires crossing the border into another country. If you start planning now using the following tips, you should be all set for a memorable conference

- Bring appropriate identification. A passport is the best form of identification. Alternatives are a birth certificate and a picture ID, such as a driver's licence or a stateissued picture ID.
- You do not need employment authorization to attend this conference. The Canada Customs and Revenue Agency produces a guidebook for associations and groups that are bringing conventions, meetings, and trade shows across the Canadian border, "Welcome to Canada: Your Guide to Bringing a Convention, Meeting, Trade Show, or Exhibition Across the Canadian Border." The book states:

"Professional organizers or planners contracted to a foreign organization holding an event in Canada, or permanent employees or members of a foreign organization, do not need employment authorization" and

"Invited foreign speakers do not need employment authorization, even if they receive funds in addition to expenses or an honorarium."

Next year's ALA Annual Conference in Toronto may seem like a long way off, but it's never too early to start making your plans for a visit to our nearest neighbor. 